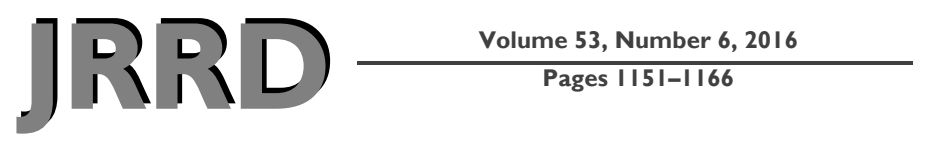

\title{
The effect of common wrist orthoses on the stiffness of wrist rotations
}

\author{
Daniel B. Seegmiller, MS; ${ }^{1}$ Dennis L. Eggett, PhD; ${ }^{2}$ Steven K. Charles, $\mathbf{P h D}^{1,3^{*}}$ \\ Departments of ${ }^{1}$ Mechanical Engineering, ${ }^{2}$ Statistics, and ${ }^{3}$ Neuroscience, Brigham Young University, Provo, UT
}

\begin{abstract}
Wrist orthoses (also known as splints, braces, or supports) are commonly used to support or restrict the motion of a weak or injured wrist. These orthoses generally function by stiffening the wrist joint. Therefore, choosing the proper orthosis (or improving orthoses) requires that we understand their stiffness properties. In this study, we present a method for measuring the stiffness of wrist orthoses, and we apply this method to 12 of the most common wrist orthoses. We found similarities and differences between these orthoses, indicating that different orthoses have different effects on the wrist joint and, presumably, on wrist behavior. In particular, all six orthoses with a stay on the volar side or the volar and dorsal sides added a significant amount of stiffness to the wrist joint. In contrast, only one of three orthoses with a stay on the dorsal side and none of the three orthoses without stays exhibited a significant amount of stiffness, calling into question their ability to support the wrist joint. This work lays a foundation for future studies investigating the effect of wrist orthosis stiffness on wrist behavior and how wrist orthosis stiffness can be designed to produce behavior that facilitates healing.
\end{abstract}

Key words: brace, impedance, joint, orthosis, splint, stiffness, support, torque, wrist, wrist injury.

\section{INTRODUCTION}

Orthoses (also known as splints, braces, or supports) are commonly prescribed or self-administered for a wide variety of disorders affecting tens of millions of patients throughout the world [1]. In 2013, Medicare alone approved payment for nearly 2.4 million orthotic codes in the amount of $\$ 734$ million [2]. Such orthoses are generally used to support or restrict the motion of a weak, deformed, diseased, or injured part of the body in an attempt to allow healing and facilitate proper function [1].

Despite their frequent use, "the state of best evidence about upper extremity orthoses is limited at best" [3]. To clarify, most upper-limb orthoses operate by adding a large amount of stiffness in parallel with the intrinsic stiffness of the joint, creating an altered state of total joint stiffness. When an orthosis is applied to a joint, the neuromuscular system must adjust to the new stiffness induced on the joint, and this can result in unintended consequences. For example, increases in forearm muscle activity during tasks requiring manipulation indicate that wrist orthosis wearers sometimes "fight against the [orthosis] to achieve the necessary wrist angle or transfer these postural deviations to the elbow, shoulder, or even the torso," potentially doing more harm than good [4-5]. Wrist orthoses have been linked to increases in shoulder muscle activation [5-7] and to deviations in shoulder position [8-10]. Although orthoses users have been shown to acclimatize somewhat to orthoses, many of the previously cited studies expressed concern that wrist

\footnotetext{
Abbreviations: $\mathrm{COM}=$ center of mass, $\mathrm{EMG}=$ electromyography, $\mathrm{FE}=$ flexion-extension, $\mathrm{MVC}=$ maximum voluntary contraction, RUD $=$ radial-ulnar deviation, $\mathrm{SD}=$ standard deviation, SRS $=$ short range stiffness, type-D $=$ dorsal stay, type- $\mathrm{N}=$ no stays, type $-\mathrm{V}=$ volar stay, type- $\mathrm{VD}=$ volar and dorsal stays.

*Address all correspondence to Steven K. Charles, PhD; Department of Mechanical Engineering, Brigham Young University, Provo, UT 84602; 801-422-7369.

Email: skcharles@byu.edu

http://dx.doi.org/10.1682/JRRD.2014.11.0274
} 
orthoses contribute to disorders of the kinematic chain (wrist, elbow, shoulder, trunk) $[9,11]$.

The first step in understanding how people adapt to orthoses is to understand how orthoses alter the stiffness of a joint, especially because similar-looking orthoses can exhibit large differences in stiffness. Therefore, the purpose of this article is to describe a method for quantitatively characterizing orthosis stiffness and to present stiffness characteristics for 12 of the most popular wrist orthoses, which are the most common type of upper-limb orthosis [3].

\section{METHODS}

\section{Subjects}

Twenty right-handed subjects (14 male, 6 female) of mean \pm standard deviation (SD) age $26 \pm 7 \mathrm{yr}$ (range 22-48 yr) were recruited through convenience sampling via word of mouth, advertisements, and a previously established volunteer list. Subjects self-reported that they were free of pain in their upper limbs and had no medical conditions affecting movement or motor control. Lefthanded subjects were excluded from this study because we desired to measure orthosis stiffness on the dominant hand and it was not practical to change the experimental setup to accommodate the left hand.

\section{Orthoses}

We are not aware of any published studies that describe the statistics of orthosis use; therefore, to focus on the most common wrist orthoses, we identified the 50 most commonly purchased orthoses using the popularity ranking on Amazon.com. Orthoses were excluded if they were not circumferential (the common, roughly cylindrically shaped orthoses with significant material wrapping all the way around the long axis of the forearm, as opposed to one-sided orthoses that are placed on either the ventral or dorsal side of the forearm and held in place with straps tightened around the forearm), interfered with the thumb or fingers, or had moving parts. According to information listed on orthosis packaging, most commercially available wrist orthoses are recommended for a large variety of wrist disorders instead of a specific wrist disorder. Because the purpose of including stays in an orthosis is to alter the stiffness of the orthosis in certain directions, we categorized the orthoses according to the location of their stay(s): volar stay (type-V), dorsal stay
(type-D), both volar and dorsal stays (type-VD), and no stays (type-N). After categorizing the top 50 orthoses, we tested whether any type was overrepresented and found that all types were represented in nearly equal proportions (Figure 1(a)), and orthoses from each type were scattered roughly evenly throughout the top 50 (Figure 1(b)). Thus, no orthosis type was dominant over others, and we included the top three orthoses of each type in this study (Table 1; Figure 2).

\section{Experimental Setup}

Our experimental setup and protocol followed a recent measurement of wrist stiffness without orthoses with minor adaptations (described subsequently) to accommodate the orthoses [13]. All measurements were performed using a wrist rehabilitation robot (InMotion Wrist Robot, Interactive Motion Technologies; Watertown, Massachusetts) that rotated subjects' wrist in combinations of flexion-extension (FE) and radial-ulnar deviation (RUD) [14]. Subjects sat next to the robot with their right arm in the parasagittal plane with the shoulder abducted $\sim 0^{\circ}$, flexed $\sim 15^{\circ}$, and humerally rotated $\sim 0^{\circ}$ and the elbow flexed $\sim 75^{\circ}$. According to the protocol (described subsequently), subjects either were wearing an orthosis or had no orthosis ("free wrist"). We describe here the setup for measurements with an orthosis, but the (a)

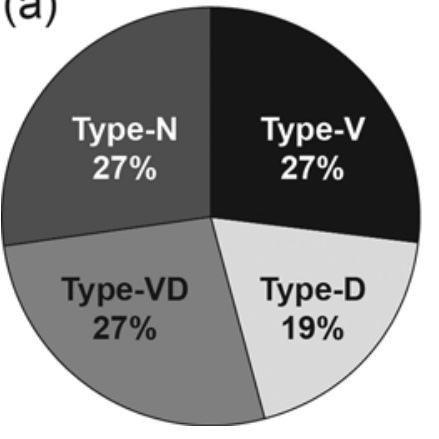

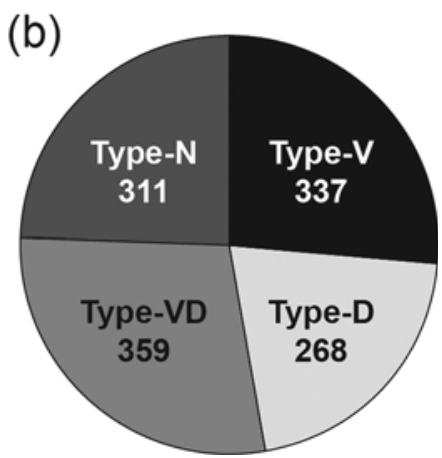

Figure 1.

Popularity of orthosis types. (a) The 50 most popular orthoses were almost equally distributed among the four orthosis types. (b) Popularity scores for each orthosis type, showing that the four types were roughly equally distributed among the top 50 orthoses. Each orthosis was scored on a scale of 1-50, with 50 being the most popular and 1 being the least popular. These scores were then summed up for each orthosis type. Type-D= dorsal stay, type- $\mathrm{N}=$ no stay, type $\mathrm{V}=$ volar stay, type $-\mathrm{VD}=$ volar and dorsal stays. 
Table 1.

Orthoses investigated in this study. Each orthosis was assigned to a type based on the location of the stay(s). The Universal Product Code (UPC) and intended use were taken from the packaging unless otherwise indicated. Different sizes of the same orthosis model have different UPCs; for simplicity we listed the UPC for only one size. Relieving carpal tunnel syndrome (CTS) was listed as the intended use for many orthoses.

\begin{tabular}{|c|c|c|c|c|c|}
\hline No. & Type & Company & Model & UPC & Intended Use \\
\hline$\overline{1}$ & $\mathrm{~V}$ & Mueller Sports Medicine* & $\begin{array}{l}\text { Adjustable Wrist } \\
\text { Brace with Splint }\end{array}$ & 074676300016 & $\begin{array}{l}\text { For CTS and weak or injured wrists; Maxi- } \\
\text { mum support level }\end{array}$ \\
\hline 2 & V & FUTURO $^{\dagger}$ & $\begin{array}{l}\text { Energizing Wrist } \\
\text { Support }\end{array}$ & 051131200609 & $\begin{array}{l}\text { Helps relieve CTS symptoms; For injured, } \\
\text { weak, or post-cast wrists; } \\
\text { Moderate stabilizing support }\end{array}$ \\
\hline 3 & $\mathrm{~V}$ & FUTURO $^{\dagger}$ & $\begin{array}{l}\text { Reversible Splint } \\
\text { Wrist Brace }\end{array}$ & 051131196773 & $\begin{array}{l}\text { For injured, weak, or post-cast wrists; } \\
\text { Moderate stabilizing support }\end{array}$ \\
\hline 4 & $\mathrm{D}$ & Brownmed, Inc & $\begin{array}{l}\text { IMAK RSI } \\
\text { SmartGlove }\end{array}$ & 649833201255 & $\begin{array}{l}\text { For CTS, arthritis, tendonitis, and } \\
\text { hand fatigue }\end{array}$ \\
\hline 5 & $\mathrm{D}$ & Tiger Paws ${ }^{\S}$ & $\begin{array}{l}\text { Tiger Paw Wrist } \\
\text { Support }\end{array}$ & $\mathrm{B} 001 \mathrm{KGH} 200^{\top}$ & $\begin{array}{l}\text { Gymnastic wrist support; help prevent } \\
\text { hyper-extension of the wrist }\end{array}$ \\
\hline 6 & $\mathrm{D}$ & Pro-Tec Athletics** & $\begin{array}{l}\text { The Clutch Wrist } \\
\text { Support }\end{array}$ & 785702026014 & For most wrist injuries, including CTS \\
\hline 7 & VD & Thermoskin $\dagger^{\dagger \dagger}$ & $\begin{array}{l}\text { Thermal Wrist/Hand } \\
\text { Brace with Dorsal Stay }\end{array}$ & 609580851691 & $\begin{array}{l}\text { Metal splint on top and bottom of wrist } \\
\text { for greater protection and support }\end{array}$ \\
\hline 8 & VD & $3 \mathrm{M}^{\dagger \dagger}$ & $\begin{array}{l}\text { ACE Brand Deluxe } \\
\text { Wrist Brace }\end{array}$ & 051131203822 & $\begin{array}{l}\text { For strains, sprains, arthritis, and repetitive } \\
\text { stress injuries; Moderate-stabilizing } \\
\text { support }\end{array}$ \\
\hline 9 & VD & FUTURO $^{\dagger}$ & Deluxe Wrist Stabilizer & 051131200906 & $\begin{array}{l}\text { Helps relieve CTS; For injured, weak, or } \\
\text { post-cast wrists; Firm stabilizing support }\end{array}$ \\
\hline 10 & $\mathrm{~N}$ & $\mathrm{Bracoo}^{\S \S}$ & $\begin{array}{l}\text { Breathable Neoprene } \\
\text { Wrist Wrap }\end{array}$ & 854194003107 & $\begin{array}{l}\text { To avoid injuries and harm; to offer } \\
\text { support and protection against outside } \\
\text { forces }{ }^{\text {IT }}\end{array}$ \\
\hline 11 & $\mathrm{~N}$ & Brownmed, Inc & $\begin{array}{l}\text { IMAK RSI Computer } \\
\text { Glove }\end{array}$ & 649833201286 & $\begin{array}{l}\text { Protect wrist from hard surface and } \\
\text { laptop heat }\end{array}$ \\
\hline 12 & $\mathrm{~N}$ & Mueller Sports Medicine* & $\begin{array}{l}\text { Wraparound Wrist } \\
\text { Support }\end{array}$ & 074676450513 & $\begin{array}{l}\text { For weak or injured wrists while maintain- } \\
\text { ing a full range of movement; Moderate } \\
\text { support level }\end{array}$ \\
\hline
\end{tabular}

*Prairie du Sac, Wisconsin.

†Cincinnati, Ohio.

Boston, Massachusetts.

$\S$ Albuquerque, New Mexico.

"Amazon Standard Identification Number is listed because a UPC could not be found.

***edmond, Washington.

$\dagger^{\dagger}$ Melbourne, Australia.

+ St. Paul, Minnesota.

$\S \S$ Fremont, California.

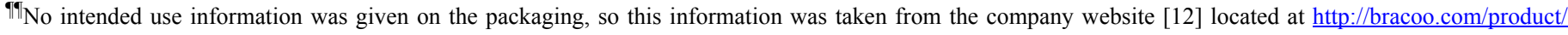
breathable-neoprene-wrist-wrap/.

$\mathrm{D}=$ dorsal stay, $\mathrm{N}=$ no stays, $\mathrm{V}=$ volar stay, $\mathrm{VD}=$ volar and dorsal stays.

setup for free-wrist measurements was the same except for the orthosis. Much care was taken to attach the subject's forearm and hand to the robot in such a way that those attachments were significantly stiffer than the stiffness of the wrist joint and orthosis, allowing us to measure the stiffness of the wrist joint and orthosis instead of the stiffness of the attachments. Each subject's forearm was strapped to the stationary stage of the robot by means of a custom bracket (Figure 3(a)), which prevented unwanted forearm motion, and the dorsal aspect of the humerus rested against an adjustable armrest (not shown). Each subject's hand was secured to the robot's end-effector using a custom-built hand-mounting frame (Figure 3(b)). This frame attached to the hand immediately 


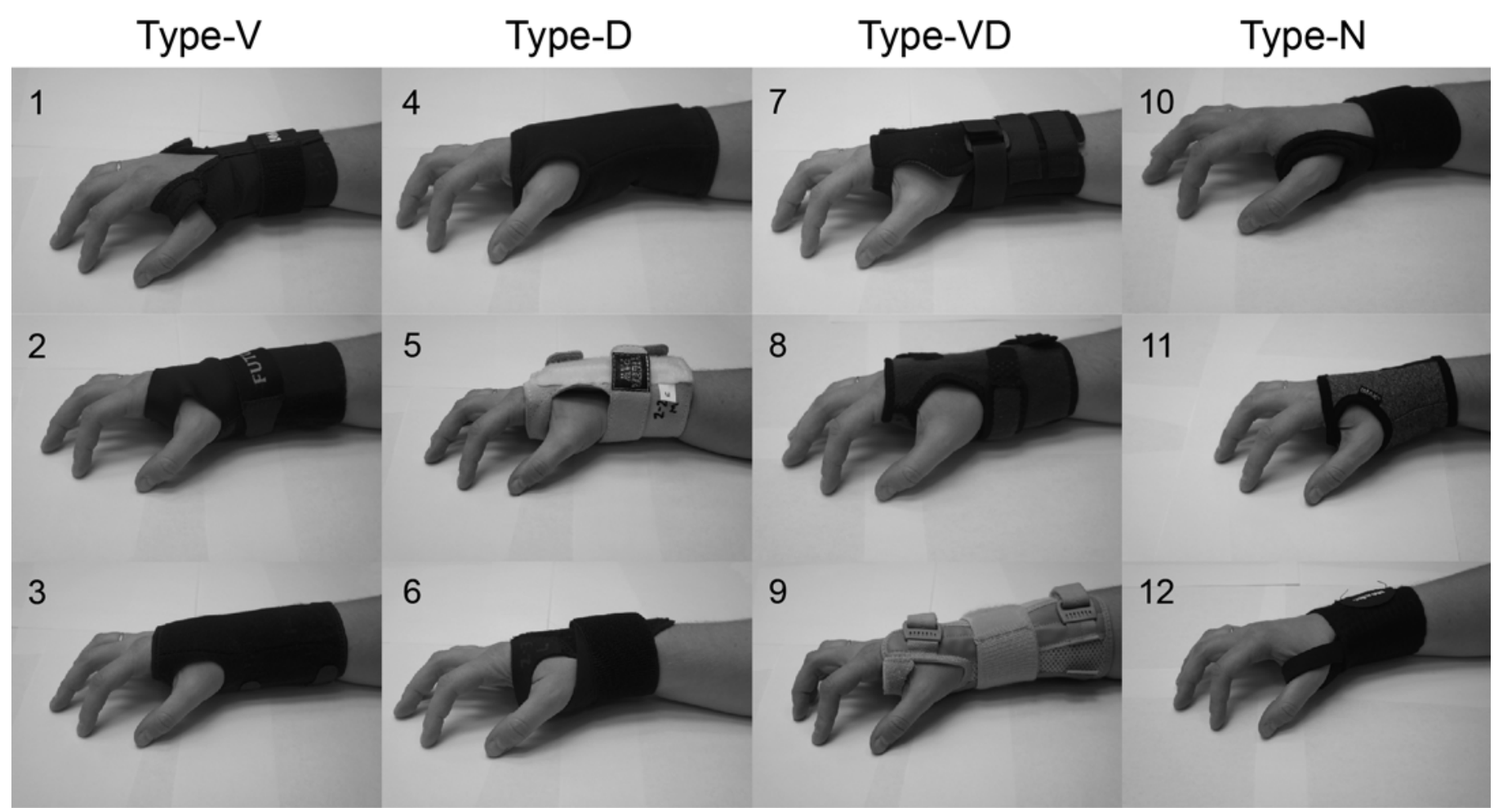

\section{Figure 2.}

Orthoses investigated in this study. Each orthosis was assigned to a type based on the location of the stay(s). Company, model, Universal Product Code, and intended use are given in Table 1. Type-D = dorsal stay, type- $\mathrm{N}=$ no stays, type- $\mathrm{V}=$ volar stay, type-VD = volar and dorsal stays.

proximal to the distal heads of the four metacarpals, but distal to the distal end of the orthosis, by means of four flat shoelace straps, which, when sufficiently tightened, allowed the end-effector to move the wrist in FE, RUD, and combinations without slippage of the hand relative to the robot. Flat shoelace straps were selected for this purpose because their large surface area and negligible axial compliance allowed us to reliably apply force to subjects' hand within an orthosis while avoiding contact between the robot and the orthosis. The appropriate strap tightness was judged to be the tightest strap configuration deemed comfortable by each subject. This setup allowed the net torque provided and measured by the robot to closely estimate the net torque the subject would have to exert to produce the same amount of displacement while wearing an orthosis.

The neutral position of the forearm and wrist was defined similar to the International Society of Biomechanics recommendations: the forearm was in neutral position halfway between pronation and supination, determined in practice by placing the dorsal tubercle of the radius and the dorsal-most protuberance of the ulnar head against a plate in the parasagittal plane [16]. The wrist was neutral in FE and RUD when the long axis of the forearm aligned with the long axis of the third metacarpal. For a subject seated at the robot, we determined this condition to be satisfied when the head of the third metacarpal, the wrist joint center, and the elbow joint center (defined midway between the medial and lateral epicondyles) were aligned. For the purposes of the calibration, the wrist joint center was defined based on the following palpable landmarks: the proximodistal location was midway between the distal end of the radius and the proximal end of the third metacarpal, the mediolateral location midway between the medial and lateral aspects of the forearm at the level of the wrist, and the ventrodorsal location midway between the ventral and dorsal aspects of the distal forearm. For all measurements, the origin of the robot's coordinate frame was adjusted to coincide with each subject's neutral position instead of the equilibrium position of the wrist inside an orthosis (i.e., the position in which the restoring torque is zero, 


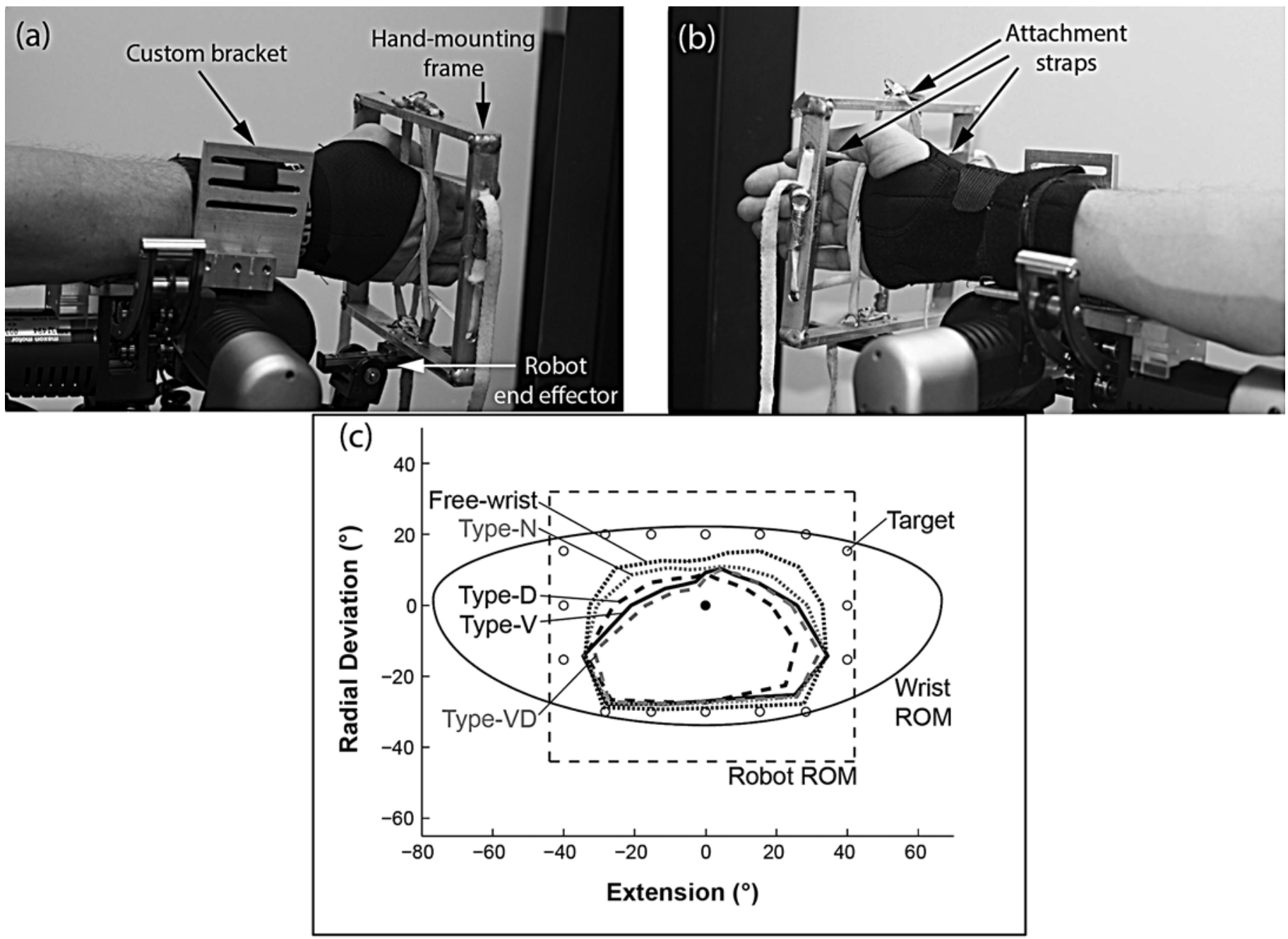

Figure 3.

Experimental setup. (a)-(b): The distal forearm was attached to the stationary stage of the robot via a custom bracket, and the hand was attached to the end effector of the robot through a custom-built hand-mounting frame. Care was taken to attach the hand, but not the orthosis, to the end effector. This was accomplished through straps tightened around the metacarpals just proximal to the metacarpophalangeal joints but distal to the orthosis. This design enabled the robot to apply torque directly to the hand, similar to the way in which a user applied torque to the orthosis. The bracket mechanically grounded the forearm to the stationary stage of the robot, preventing unwanted rotation and translation of the forearm during measurement. (c) The robot was programmed to travel from the center target (solid circle) to 16 peripheral targets (open circles), shown here in context of the range of motion (ROM) of the robot and the approximate ROM of the wrist (adapted from An et al.15]). The range of motion actually reached by the robot is also shown, averaged for the five types of stiffness measurement (free-wrist and 4 orthosis types). Negative extension and radial deviation indicate flexion and ulnar deviation, respectively. Type- $\mathrm{D}=$ dorsal stay, type- $\mathrm{N}=$ no stays, type- $\mathrm{V}=$ volar stay, type-VD = volar and dorsal stays.

which is different for different orthoses), allowing us to compare the stiffness of different orthoses relative to a common reference point (neutral position).

Measuring orthosis stiffness also involved measurements of intrinsic wrist joint stiffness (described subsequently). Joint stiffness is known to change with muscle activation [17]. Therefore, subjects were asked to remain passive during all measurements by relaxing their upper limb and not resisting the robot. To monitor whether subjects remained passive, we measured wrist muscle activity in the flexor carpi radialis, flexor carpi ulnaris, extensor carpi radialis (longus and brevis together), and extensor 
carpi ulnaris using surface electromyography (EMG) sensors (Trigno Wireless EMG, Delsys, Inc; Natick, Massachusetts) recording at $200 \mathrm{~Hz}$. Because we only needed average EMG (explained subsequently), this sampling frequency was sufficiently high [18].

\section{Protocol}

The 20 subjects were randomly assigned to one of the four orthosis types. Each subject participated in a single $2 \mathrm{~h}$ measurement session consisting of four individual stiffness measurements: first without an orthosis (freewrist) and then while wearing each of the three orthoses of the type to which the subject was assigned. The order of the orthoses was randomized for each subject. All available sizes were purchased for each orthosis, and subjects wore the orthosis size with the best fit. Each measurement lasted approximately $20 \mathrm{~min}$, and subjects were allowed a short break $(<15 \mathrm{~min})$ in between measurements, but most subjects chose to continue to the next measurement without a break. No restrictions were placed on wrist activity prior to the experiment. All measurements were performed by the same researcher, who was thoroughly trained by researchers involved in previous measurements of wrist stiffness [18-19].

All measurements, whether with or without orthosis, followed the same protocol. In each measurement, the robot moved subjects' wrists between neutral position and 16 targets spaced every $22.5^{\circ}$ throughout FE and RUD (Figure 3(c)), moving to each target three times before moving on to the next target. The robot moved slowly, with an average velocity for the free-wrist measurements of approximately $5 \%$, and followed a smooth (minimumjerk) trajectory to avoid triggering reflexes. Immediately prior to their session, subjects were given a brief overview of how the robot functioned and given advice on how to let the robot move their passive wrist without inadvertently assisting or resisting the motion. Robot motion was controlled through proportional-derivative control, with a proportional gain of $10.0 \mathrm{Nm} / \mathrm{rad}$ and a derivative gain of $0.1 \mathrm{Nm} / \mathrm{rad}$. The movement toward each target terminated when the target was reached within allowable controller gain error or when the torque limit of the robot (2.0 Nm in FE and RUD) was reached. The effect of short range stiffness (SRS), which is known to affect the first $3^{\circ}$ to $4^{\circ}$ of movement, was accounted for by starting $3^{\circ}$ in front of the nominal start position and excluding those $3^{\circ}$ from the analysis [20]. After the four stiffness measurements were performed, we measured subjects' EMG during maximum voluntary contraction (MVC) in wrist flexion and extension to allow for normalization of the EMG data.

\section{Data Processing}

EMG data for all movements were detrended, rectified, and low-pass filtered using a second-order Butterworth filter with a cutoff frequency of $3 \mathrm{~Hz}$. EMG data for each muscle were normalized by the MVC of that muscle. Following a recent measurement characterizing the stiffness of the wrist and forearm, any movement with a mean EMG greater than 6 percent of MVC was excluded from the analysis as being a "nonpassive" movement [18].

The data recorded during the measurements included the angular displacement of the wrist and the robot torque required to produce that angular displacement, both as a function of time. The torque-displacement data for each orthosis and free-wrist condition were separated into 96 individual movements: three outbound and three inbound movements for each of the 16 targets. (Outbound movements are movements from the center target to a peripheral target, and inbound movements are movements from a peripheral target to the center target.) The SRS band was removed from each outbound and inbound movement. In part because of the added stiffness of the orthoses, the robot often hit its torque limit $(2.0 \mathrm{Nm})$ before reaching the programmed targets (Figure 3(c)), resulting in sections of data during which the robot was saturated. We compensated for this saturation by trimming the data set to exclude all data recorded after the robot saturated.

Because motor saturation occurred earliest for movements in the stiffest directions, these data sets, when trimmed, were considerably shorter than those in directions of lowest stiffness. Following the previous approach of obtaining the stiffness matrix by performing a multiple linear regression over the entire field would have artificially skewed stiffness measurements toward lower stiffness because movements in low-stiffness directions had more data points [18-19]. We corrected for this by first performing a multiple linear regression for each target separately (over its three repetitions), calculating the stiffness matrix associated with each target, and interpolating an evenly distributed torque field for that target from the calculated stiffness matrix. Because the stiffness was generally anisotropic (different in different directions), the torque vector required to move in a given direction did not generally align with that direction. Therefore, a matrix (instead of a scalar) was required to describe the stiffness in each direction. We then performed a multiple linear regression over 
the combined torque field for all targets as described in Drake and Charles and Formica et al. [18-19]. This eliminated the bias resulting from differences in movement length and the number of data points between directions.

Torques because of gravity and robot dynamics varied with the position of the end effector and, unless removed, would artificially add an effective stiffness to the inherent stiffness of the wrist and orthosis. Although the magnitude of these artifacts is relatively small (see Figure 4 in Drake and Charles [18]), we removed these effects for each subject as follows. We used anthropometric data to estimate the mass of each subject's hand and attached this mass to the robot end-effector according to each subject's recorded neutral position and center-ofmass position in the hand frame [21]. The standard robot protocol was then re-run for each subject with a mass instead of the subject's hand, and the resulting data were used to produce a unique "compensation matrix" for each subject. This compensation matrix was then subtracted from the four stiffness matrices, resulting in four intermediate stiffness matrices. Finally, we subtracted from these four intermediate stiffness matrices the intrinsic stiffness of the wrist joint measured in the free-wrist condition to obtain the stiffness of each orthosis.

\section{Data Analysis}

As in prior work, the stiffness of each orthosis was expressed as the more intuitive characteristics of the ellipse associated with the symmetric portion of the stiffness matrix [13,19,22-23]. The antisymmetric portion of the stiffness ellipse is typically negligible; this is confirmed in the "Results" section [13,18-19]. More specifically, our outcome measures included the area, anisotropy, and orientation of the stiffness ellipse, which represent the overall amount of stiffness, the ratio of largest to smallest stiffness, and the direction of greatest stiffness, respectively. The area and anisotropy were calculated as $\pi \lambda_{1} \lambda_{2}$ and $\lambda_{1} / \lambda_{2}$, respectively, where $\lambda_{1}$ and $\lambda_{2}$ are the eigenvalues of the symmetric portion of the stiffness matrix, and $\lambda_{1}>\lambda_{2}$. The orientation was defined as the angle measured counterclockwise from the RUD axis to the major axis of the stiffness ellipse, which is given by the eigenvector associated with $\lambda_{1}$.

Because the stiffness ellipse is derived from the stiffness matrix, which is a linear approximation of the torquedisplacement field, it does not account for asymmetries. For example, an orthosis that is stiffer in flexion than extension would appear to be the same in both directions. To determine asymmetry in orthosis stiffness, we also computed the stiffness in each movement direction separately, as opposed to regressing over all movement directions at once, and plotted the stiffness as a function of direction in polar plot form, where greater distance from the origin indicates greater stiffness in that direction (see "Fitting Ellipse Method" in Formica et al. [19]). We then obtained a measure of the asymmetry in stiffness by calculating the location of the center of mass (COM) of this polar plot, resulting in two additional outcome measures: $\mathrm{COM}_{\mathrm{FE}}$ and $\mathrm{COM}_{\mathrm{RUD}}$. Positive values of $\mathrm{COM}_{\mathrm{FE}}$ and $\mathrm{COM}_{\mathrm{RUD}}$ indicate that the orthosis is stiffer in extension and radial deviation than in flexion and ulnar deviation.

To compare outcome measures between orthoses, we performed a mixed-models analysis of covariance with blocking on subject, including free-wrist values as covariate. The model included orthosis type and model as factors and accounted for the type by orthosis interaction. This allowed us to do pairwise tests between different types of orthoses and pairwise tests between individual orthoses within each type using a Tukey-Kramer adjustment for multiple comparisons.

\section{RESULTS}

On average, 98 percent of all outbound and of all inbound movements had EMG below the 6 percent MVC threshold. Of the 80 stiffness measurements, 67 had zero EMG rejections. Of the 13 stiffness measurements that experienced EMG rejections, all had exclusion rates below 30 percent.

The multiple linear regressions showed very high goodness-of-fit values, indicating that stiffness was well approximated by a linear fit. The average $r^{2}$ value for the stiffness matrices was $0.94 \pm 0.04$ (mean $\pm \mathrm{SD}$ ), and the average $r^{2}$ value for the COM stiffness calculations was $0.96 \pm 0.05$. As expected, the antisymmetric portion of the stiffness matrices was negligible, accounting on average for only 3 percent of the total (symmetric + antisymmetric) stiffness.

\section{Measures for Individual Orthoses}

Orthoses of the same type generally had similar measures (Table 2, Figures 4-5). Two exceptions were found within type-D and type-VD orthoses. Among the type-D orthoses, orthosis 5 had significantly greater area than orthoses 4 and $6(p<0.002)$ and significantly greater $\mathrm{COM}_{\mathrm{FE}}$ than orthosis $4(p=0.001)$. This can be attributed to the fact that orthosis 5 is intended for use in tumbling 
JRRD, Volume 53, Number 6, 2016

Table 2.

Stiffness characteristics for each orthosis, with 95 percent confidence intervals in parentheses.

\begin{tabular}{|c|c|c|c|c|c|c|}
\hline Orthosis & Type & Area, $\mathrm{N}^{2} \mathrm{~m}^{2}$ & Anisotropy & Orientation, $^{\circ}$ & $\mathrm{COM}_{\mathrm{FE}}, \mathrm{Nm}$ & $\mathrm{COM}_{\text {RUD }}, \mathrm{Nm}$ \\
\hline \multirow{2}{*}{1} & \multirow{2}{*}{ V } & $11.9^{*}$ & $1.4^{\dagger}$ & 22.7 & -0.1 & $0.8^{\dagger}$ \\
\hline & & $(-0.2$ to 24.1$)$ & (1.1 to 1.7$)$ & $(-2.6$ to 48.0$)$ & $(-0.4$ to 0.2$)$ & $(0.4$ to 1.2$)$ \\
\hline \multirow[t]{2}{*}{2} & \multirow[t]{2}{*}{ V } & $18.5^{*}$ & $1.4^{\dagger}$ & 21.8 & -0.2 & $1.1^{\dagger}$ \\
\hline & & $(6.4$ to 30.7$)$ & (1.1 to 1.7$)$ & $(-3.5$ to 47.1$)$ & $(-0.6$ to 0.1$)$ & $(0.7$ to 1.5$)$ \\
\hline \multirow[t]{2}{*}{3} & \multirow[t]{2}{*}{$\mathrm{V}$} & $17.2^{*}$ & $1.4^{\dagger}$ & $46.5^{\dagger}$ & $-0.4^{*}$ & $1.0^{\dagger}$ \\
\hline & & (5.1 to 29.4$)$ & (1.1 to 1.8$)$ & (21.2 to 71.7$)$ & $(-0.7$ to -0.1$)$ & $(0.6$ to 1.4$)$ \\
\hline \multirow[t]{2}{*}{5} & \multirow[t]{2}{*}{$\mathrm{D}$} & $46.4^{\dagger}$ & $1.8^{\dagger}$ & $31.9^{*}$ & $1.1^{\dagger}$ & $1.3^{\dagger}$ \\
\hline & & (34.1 to 58.8 ) & (1.5 to 2.2$)$ & $(6.5$ to 57.4$)$ & $(0.7$ to 1.4$)$ & (0.9 to 1.7$)$ \\
\hline \multirow[t]{2}{*}{6} & \multirow[t]{2}{*}{$\mathrm{D}$} & 8.0 & $1.8^{\dagger}$ & $36.9^{*}$ & $0.3^{*}$ & $0.5^{*}$ \\
\hline & & $(-4.4$ to 20.3$)$ & (1.5 to 2.2 ) & (11.4 to 62.3$)$ & $(0.0$ to 0.7$)$ & $(0.1$ to 0.9$)$ \\
\hline 7 & VD & $29.9^{\dagger}$ & $1.4^{\dagger}$ & $46.7^{\dagger}$ & $-0.3^{*}$ & $1.3^{\dagger}$ \\
\hline \multirow[t]{2}{*}{9} & \multirow[t]{2}{*}{ VD } & $29.0^{\dagger}$ & $1.7^{\dagger}$ & 22.4 & $-0.9^{\dagger}$ & $1.3^{\dagger}$ \\
\hline & & (16.8 to 41.3 ) & (1.4 to 2.0$)$ & $(-3.0$ to 47.7$)$ & $(-1.2$ to -0.6$)$ & $(0.9$ to 1.7$)$ \\
\hline \multirow[t]{2}{*}{10} & \multirow[t]{2}{*}{$\mathrm{N}$} & 1.4 & $2.3^{\dagger}$ & -4.8 & 0.1 & -0.1 \\
\hline & & $(-12.2$ to 14.9$)$ & (1.9 to 2.6$)$ & $(-33.1$ to 23.6$)$ & $(-0.2$ to 0.4$)$ & $(-0.5$ to 0.3$)$ \\
\hline \multirow[t]{2}{*}{11} & \multirow[t]{2}{*}{$\mathrm{N}$} & -0.8 & $1.6^{\dagger}$ & 12.0 & 0.2 & -0.3 \\
\hline & & $(-14.4$ to 12.8$)$ & (1.2 to 1.9$)$ & $(-16.4$ to 40.3$)$ & $(-0.2$ to 0.5$)$ & $(-0.7$ to 0.1$)$ \\
\hline \multirow[t]{2}{*}{12} & \multirow[t]{2}{*}{$\mathrm{N}$} & -0.1 & $1.8^{\dagger}$ & 6.1 & 0.1 & -0.0 \\
\hline & & $(-13.7$ to 13.5$)$ & (1.4 to 2.1$)$ & $(-22.3$ to 34.4$)$ & $(-0.3$ to 0.4$)$ & $(-0.4$ to 0.4$)$ \\
\hline
\end{tabular}

${ }^{*} p \leq 0.05$.

$\dagger^{\dagger} p 0.001$.

$\mathrm{COM}=$ center of mass, $\mathrm{D}=$ dorsal stay, $\mathrm{FE}=$ flexion extension, $\mathrm{N}=$ no stays, $\mathrm{RUD}=$ radial-ulnar deviation, $\mathrm{V}=$ volar stay, $\mathrm{VD}=$ volar and dorsal stays.

gymnastics and hence is much stiffer (Table 1). Among the type-VD orthoses, orthosis 9 had significantly lower $\mathrm{COM}_{\mathrm{FE}}$ than orthosis $8(p<0.05)$. There were no other statistically significant differences between orthoses of the same type.

\section{Mean Measures for Orthosis Types}

On average, type- $\mathrm{V}$, type- $\mathrm{D}$, and type-VD orthoses had statistically significant amounts of area, anisotropy, and orientation (Table 3). We note, however, that individually, two of the three type-D orthoses failed to exhibit a significant amount of area (Table 2). We also found significant amounts of $\mathrm{COM}_{\mathrm{FE}}$ and $\mathrm{COM}_{\mathrm{RUD}}$ : as expected, type- $\mathrm{V}$ orthoses were stiffer in flexion than in extension, and type-D orthoses were stiffer in extension than in flexion. Type-VD orthoses were stiffer in flexion than extension. Type- $\mathrm{V}$, type-D, and type-VD orthoses were stiffer in radial deviation than in ulnar deviation; this was true not only for the mean of each type (Table 3) but also for each individual orthosis (Table 2). In contrast, type-N orthoses did not exhibit statistically significant amounts of area, orientation, $\mathrm{COM}_{\mathrm{FE}}$, or $\mathrm{COM}_{\mathrm{RUD}}$. This was true for all type-N orthoses together (Table 3) and individually (Table 2).

\section{Comparison Between Orthosis Types}

Type-VD orthoses were more similar to type-V orthoses than to type-D orthoses (Table 4). The only statistically significant difference between type- $\mathrm{V}$ and type-VD orthoses was that type-VD orthoses had greater area; this greater stiffness can be attributed to the fact that type-VD have two stays, whereas type- $\mathrm{V}$ orthoses only have one. Compared with type-V and type-VD orthoses, type-D orthoses had significantly greater anisotropy and $\mathrm{COM}_{\mathrm{FE}}$ (indicating that the stiffness in extension was greater than in flexion). Type-N orthoses exhibited statistically significant differences with respect to all the other types of orthoses (Table 4). 
(a)

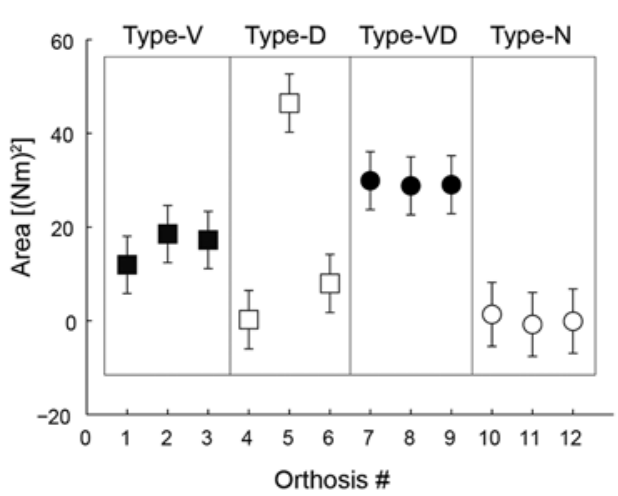

(b)

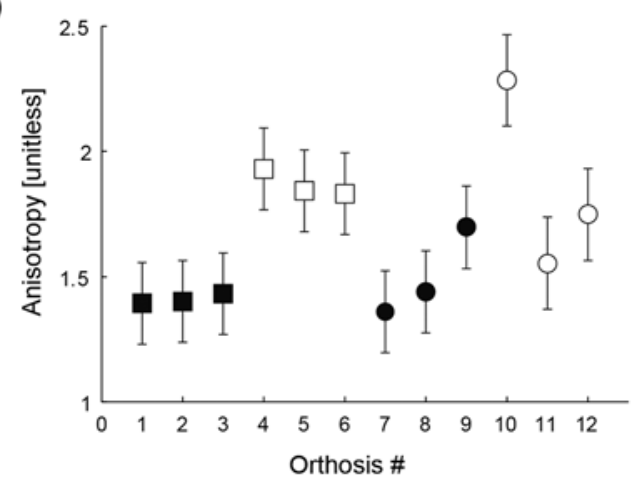

(d)

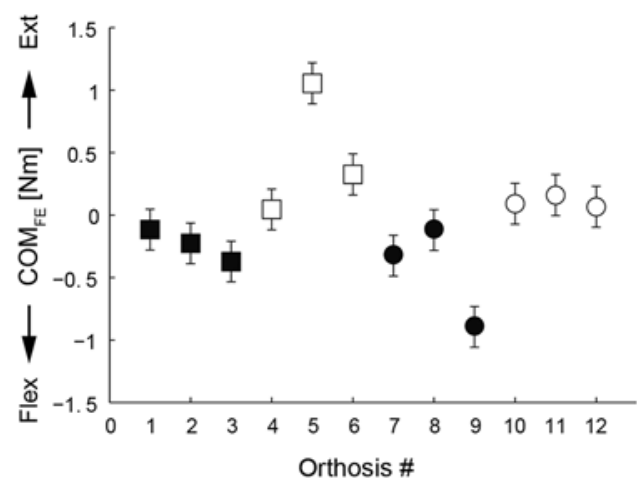

(e)

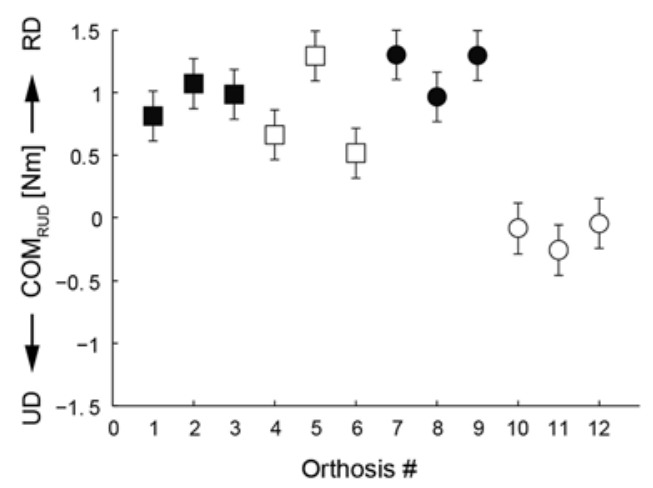

(c)

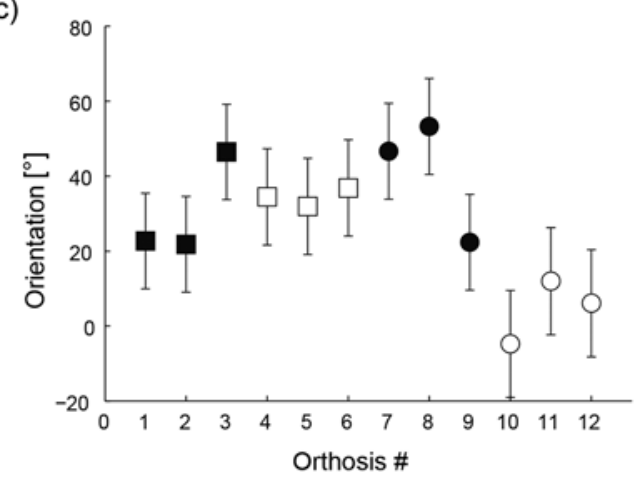

Figure 4.

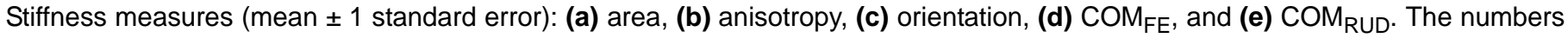
on the horizontal axis of each subplot indicate orthosis number (Table 1). Each type of orthosis is indicated by a different symbol, as indicated in (a). Positive values of (d) $\mathrm{COM}_{\mathrm{FE}}$ and (e) $\mathrm{COM}_{\mathrm{RUD}}$ indicate that the orthosis is stiffer in extension (Ext) and radial deviation (RD) than in flexion (Flex) and ulnar deviation (UD). COM = center of mass, FE = flexion-extension, RUD = radial-ulnar deviation, type-D = dorsal stay, type- $\mathrm{N}=$ no stays, type- $\mathrm{V}=$ volar stay, type-VD = volar and dorsal stays.

\section{DISCUSSION}

Understanding how wrist orthoses affect the stiffness of wrist rotations is a key factor in understanding their effects on wrist movement behavior and subsequently improving their performance. To date, however, no studies have measured the stiffness of wrist orthoses. Therefore, the purpose of this article was to propose a method for quantifying orthosis stiffness and to characterize the most common types of wrist orthoses. We chose to characterize four different types of orthoses, with three orthoses per type. We found that (1) three out of four orthosis types 
significantly altered the stiffness of wrist rotations, (2) in general, orthoses of the same type were not significantly different from each other, and (3) there were important similarities and differences in stiffness between different types of orthoses.

\section{Comparison to Prior Studies}

Although there have been no prior measurements of wrist orthosis stiffness, we found indirect evidence confirming our results. First, we compared our free-wrist stiffness measurements to the two prior measurements of wrist stiffness (without orthoses) in FE and RUD [13,19]. Our mean ellipse area (mean $\pm \mathrm{SD}$ ) of $6.3 \pm 4.7(\mathrm{Nm})^{2}$ was similar to the prior measurements of $5.6 \pm 3.5(\mathrm{Nm})^{2}$ and $5.9 \pm 3.0(\mathrm{Nm})^{2}[13,19]$. Our mean ellipse orientation of $9.7 \pm 5.1^{\circ}$ was similar to $12.1 \pm 4.7^{\circ}$ (Pando et al.) but lower than $26.0 \pm 10.6^{\circ}$ (Formica et al.; see Pando et al. for an explanation of the difference in orientation between Pando et al. and Formica et al.) [13,19]. We also compared our measurements of $\mathrm{COM}_{\mathrm{FE}}$ and $\mathrm{COM}_{\mathrm{RUD}}$ with the only prior measurement, Formica et al., and found that our mean values of $0.1 \pm 0.2 \mathrm{Nm}$ and $-0.8 \pm$ $0.7 \mathrm{Nm}$ in FE and RUD were similar to that study's mean values of $0.1 \pm 0.2 \mathrm{Nm}$ and $-0.5 \pm 0.2 \mathrm{Nm}$ [19]. Second, our finding that orthoses within the same type are generally not significantly different from one another correlates to the observation that similar wrist orthoses cause similar reductions in wrist range of motion because orthoses with similar stiffness will produce similar displacements for a given torque input [24]. Similarly, our finding that type- $\mathrm{V}$, type-D, and type-VD orthoses significantly altered the stiffness of the wrist joint is in agreement with the common conclusion that wrist orthoses reduce the maximal wrist range of motion [8,25-27].

\section{Implications}

The most immediate and interesting implication of this research involves our comparison between orthosis types. Type-V and type-VD orthoses were shown to be similar in all measures except area. This means that type-VD orthoses provide greater resistance to movement, but the direction and distribution of resistance is the same even though the former are generally more expensive. From a clinical point of view, this indicates that if a subject's condition does not require the stronger type-VD orthosis, it may be possible to substitute a type- $\mathrm{V}$ orthosis without a change in the direction or distribution of resistance. This is true for any of the three type- $\mathrm{V}$ orthoses because they are not significantly different from one another. However, this reasoning does not extend to type$\mathrm{D}$ or type-N orthoses because they have distinct properties from the other types. The typically plastic or metal stay in a type-D orthosis shifts stiffness more into extension (greater $\mathrm{COM}_{\mathrm{FE}}$ ) and causes a different amount of anisotropy than the stays in type- $\mathrm{V}$ and type-VD orthoses. Type-N orthoses are different from all of the other types; while type- $\mathrm{V}$, type-D, and type-VD orthoses exhibit a statistically significant amount of stiffness, type-N orthoses do not (Table 3). This implies that type-N orthoses do not significantly increase the stiffness of the wrist joint, calling into question their utility in stabilizing, immobilizing, or supporting the wrist joint. Nonetheless, they may encourage joint healing by discouraging joint use, either by reminding the wearer of an injury or by making the use of that limb less desirable because the orthosis obstructs the palm and reduces sensory feedback from the palm.

\section{Effects on Wrist Behavior}

Although changes in wrist behavior are most easily ascribed to the increase in the overall stiffness (area) that accompanies the use of most orthoses, the other measures are each capable of changing wrist behavior as well, thus complicating exactly how wrist orthoses alter wrist behavior. To elucidate, coordinated wrist movement requires that the neuromuscular system account for all aspects of stiffness, including anisotropy, orientation, $\mathrm{COM}_{\mathrm{FE}}$, and $\mathrm{COM}_{\mathrm{RUD}}$, because each of these measures alters the relationship between applied muscle force and the ensuing movement [28-30]. For example, many common tasks involving the wrist utilize the "dart thrower's motion," which takes advantage of the direction of lowest stiffness in the joint $[19,31]$. Indeed, we expect that changes to wrist stiffness involving anisotropy, orientation, $\mathrm{COM}_{\mathrm{FE}}$, and $\mathrm{COM}_{\mathrm{RUD}}$ generally necessitate more neuromuscular adjustments than do changes to the area because changes to the former characteristics alter the preferred or easiest direction of motion and require different patterns of muscle activation to obtain the same target, while changes to area only necessitate more or less of the same muscle activation pattern. Though a few studies have investigated the effect of orthosis use on muscle activity, no studies to date have investigated the effect of orthosis properties (area, anisotropy, orientation, $\mathrm{COM}_{\mathrm{FE}}, \mathrm{COM}_{\mathrm{RUD}}$ ) on changes in muscle activity, either short term or after adaptation [4-5]. 
(a)

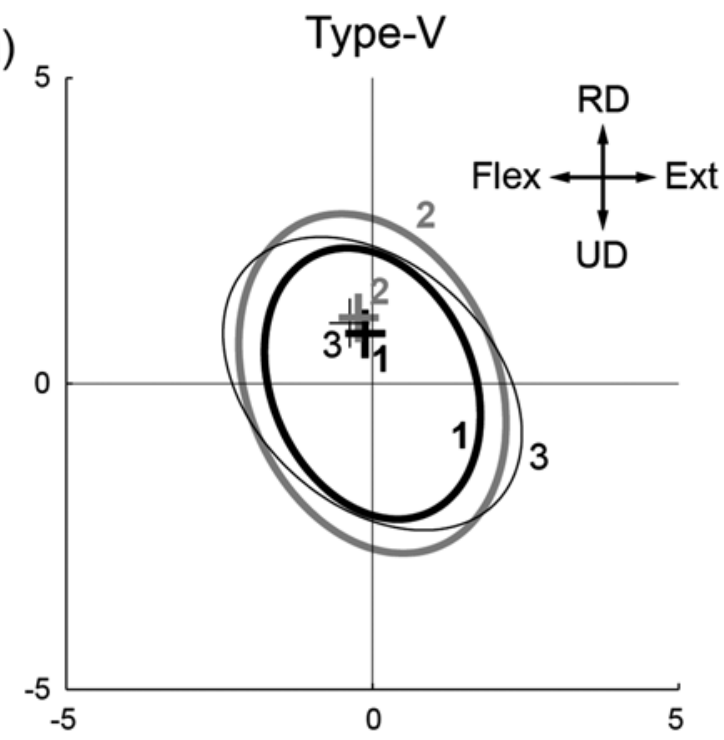

(c)

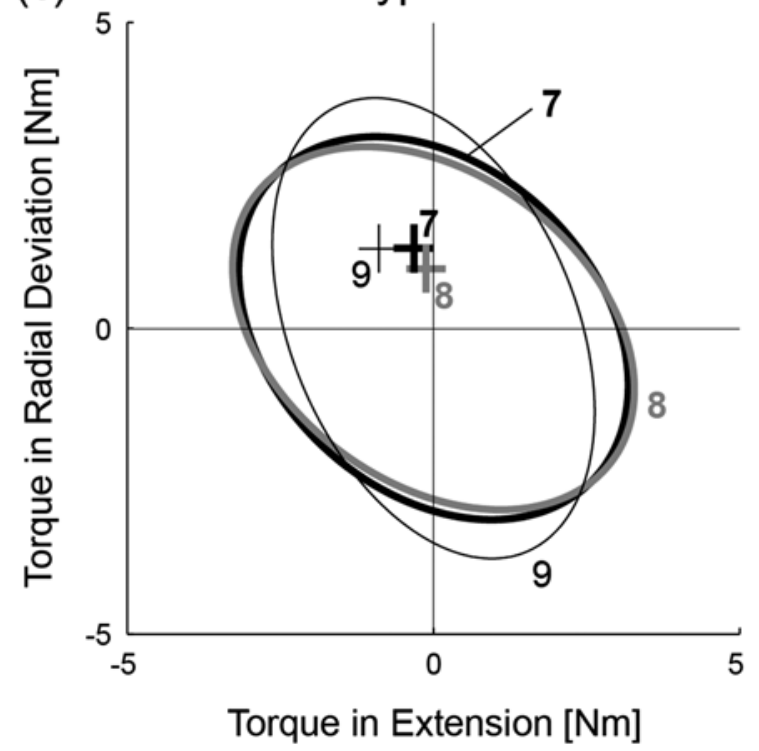

(b)

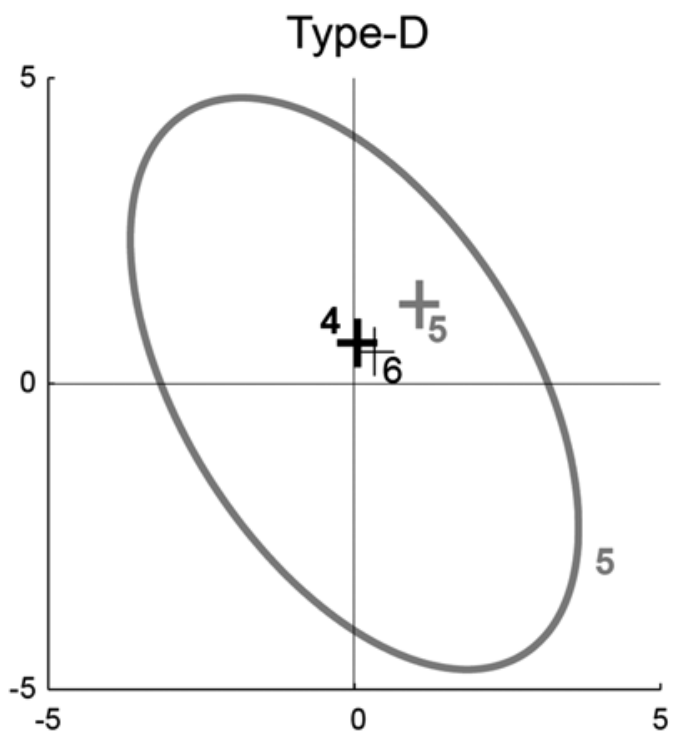

(d)

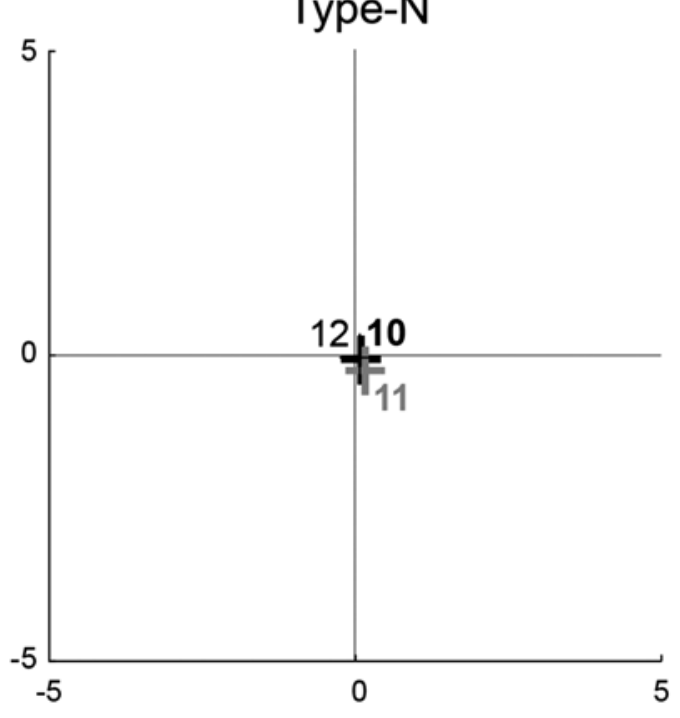

Figure 5.

Mean stiffness ellipses and $\mathrm{COM}_{\mathrm{FE}} / \mathrm{COM}_{\mathrm{RUD}}$ error bars for each orthosis, grouped by type: (a) type-V, (b) type-D, (c) type-VD, and (d) type-N. Ellipses and $\mathrm{COM}_{\mathrm{FE}} / \mathrm{COM}_{\mathrm{RUD}}$ error bars are labeled with the orthosis number (Table 1). Ellipses were not included for orthoses 4, 6, 10, 11, and 12 because their areas were not statistically different from zero (Table 2). The axis labels in (c) represent the axis labels for all subfigures. Negative torque in radial deviation (RD) and extension (Ext) represent torque in flexion (Flex) and ulnar deviation (UD), respectively. Larger ellipses represent greater orthosis stiffness. Directions of greatest and least stiffness are indicated by the major and minor axes, respectively. The $\mathrm{COM}_{\mathrm{FE}} / \mathrm{COM} \mathrm{M}_{\mathrm{RUD}}$ error bars represent the mean and 95 percent confidence intervals in FE and RUD. Error bars with means in Ext and RD (e.g., orthosis 5) indicate that the orthosis is stiffer in Ext and RD than in Flex and UD. The error bars for orthoses 10 and 12 are almost indistinguishable. COM = center of mass, FE = flexionextension, RUD = radial-ulnar deviation, type $\mathrm{D}=$ dorsal stay, type- $\mathrm{N}=$ no stays, type- $\mathrm{V}=$ volar stay, type-VD = volar and dorsal stays. 
Table 3.

Mean stiffness characteristics for each type of orthosis, with 95 percent confidence intervals in parentheses.

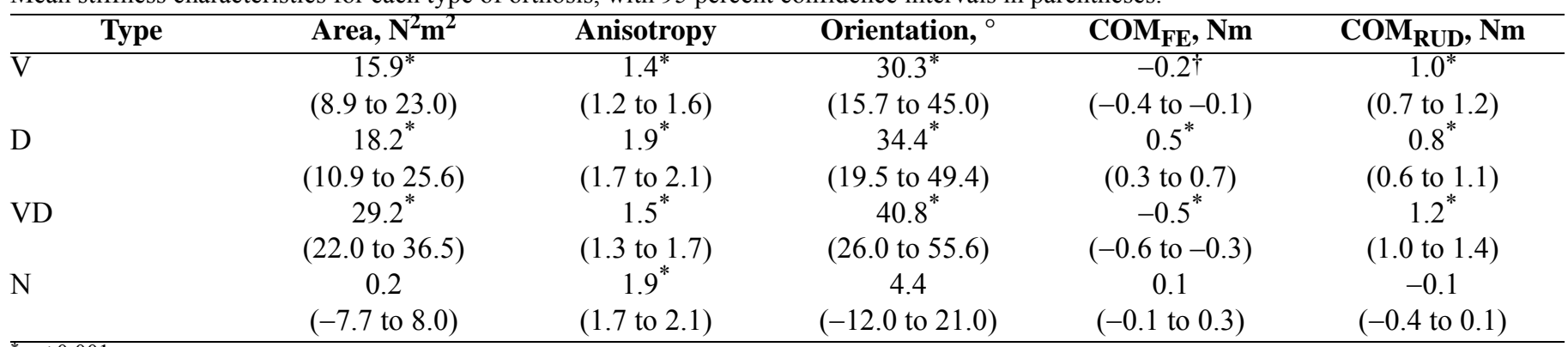

${ }^{*} p \leq 0.001$.

$\dagger^{\dagger} p \leq 0.05$.

$\mathrm{COM}=$ center of mass, $\mathrm{D}=$ dorsal stay, $\mathrm{FE}=$ flexion-extension, $\mathrm{N}=$ no stays, $\mathrm{RUD}=$ radial-ulnar deviation, $\mathrm{V}=$ volar stay, $\mathrm{VD}=\mathrm{volar}$ and dorsal stays.

Table 4.

Differences between orthosis types, with 95 percent confidence intervals in parentheses. Only statistically significant differences $(p \leq 0.05)$ are listed.

\begin{tabular}{|c|c|c|c|c|c|}
\hline Comparison & Area, $\mathbf{N}^{2} \mathbf{m}^{2}$ & Anisotropy & Orientation, $^{\circ}$ & $\mathrm{COM}_{\mathrm{FE}}, \mathrm{Nm}$ & $\mathrm{COM}_{\text {RUD }}, \mathrm{Nm}$ \\
\hline Type-V vs Type-D & - & $\begin{array}{c}-0.5^{*} \\
(-0.8 \text { to }-0.1)\end{array}$ & - & $\begin{array}{c}-0.7^{\dagger} \\
(-1.1 \text { to }-0.4)\end{array}$ & - \\
\hline Type-V vs Type-VD & $\begin{array}{c}-13.3^{*} \\
(-26.4 \text { to }-0.3)\end{array}$ & - & - & - & - \\
\hline Type-V vs Type-N & $\begin{array}{c}15.7^{*} \\
(1.8 \text { to } 29.7)\end{array}$ & $\begin{array}{c}-0.5^{*} \\
(-0.8 \text { to }-0.1)\end{array}$ & - & - & $\begin{array}{c}1.1^{*} \\
(0.5 \text { to } 1.4)\end{array}$ \\
\hline Type-D vs Type-VD & - & $\begin{array}{c}0.4^{*} \\
(0.0 \text { to } 0.7)\end{array}$ & - & $\begin{array}{c}0.9^{\dagger} \\
(0.6 \text { to } 0.1)\end{array}$ & - \\
\hline Type-D vs Type-N & $\begin{array}{c}18.1^{*} \\
(4.1 \text { to } 32.0)\end{array}$ & - & $\begin{array}{c}30.0^{*} \\
(0.2 \text { to } 59.7)\end{array}$ & $\begin{array}{c}0.4^{*} \\
(0.0 \text { to } 0.7)\end{array}$ & $\begin{array}{c}1.0^{\dagger} \\
(0.6 \text { to } 2.1)\end{array}$ \\
\hline Type-VD vs Type-N & $\begin{array}{c}29.1^{\dagger} \\
(14.8 \text { to } 43.3)\end{array}$ & - & $\begin{array}{c}36.3^{*} \\
(7.5 \text { to } 65.1)\end{array}$ & $\begin{array}{c}-0.6^{\dagger} \\
(-0.9 \text { to }-0.2)\end{array}$ & $\begin{array}{c}1.3^{\dagger} \\
(0.9 \text { to } 1.8)\end{array}$ \\
\hline
\end{tabular}

${ }^{*} p \leq 0.05$.

$\dagger p \leq 0.001$.

$\mathrm{COM}=$ center of mass, $\mathrm{FE}=$ flexion-extension, $\mathrm{RUD}=$ radial-ulnar extension, type- $\mathrm{D}=$ dorsal stay, type- $\mathrm{N}=$ no stays, type- $\mathrm{V}=$ volar stay, type- $\mathrm{VD}=$ volar and dorsal stays.

In addition, the popularity of type-N orthoses, which are purchased in equal proportions to the other three types (Figure 1), demonstrates that orthoses may play more than a mechanical role in healing. Further research is required to ascertain whether type- $\mathrm{N}$ orthoses significantly alter wrist rotation behavior, and if they do so through nonmechanical means such as psychological effects. Because type-N orthoses do not significantly alter the stiffness of wrist rotations, they could perhaps be used to identify the nonmechanical effects of orthoses on wrist rotation behavior.

\section{Limitations}

We performed the stiffness measurements using one of very few commercially available robots designed to rotate the human wrist in multiple degrees of freedom. The robot is meant for safe interaction with humans, and its motors commonly saturated before the end of the range of motion of the wrist was reached, reducing the range over which the orthoses were characterized. Although we minimized the bias for less stiff directions during data processing, a robot with stronger motors would have characterized the orthoses over a greater range of motion.

Another limitation of this study was the modest number of orthoses characterized in each type. Although our stiffness measurements reflect the most popular orthoses, it is unclear how well they represent the stiffness of all orthoses of each type. Additionally, the orthoses used in this study are more likely to be self-administered than 
prescribed, and our results do not necessarily reflect properties of prescription orthoses. Also, each orthosis was measured with only five subjects. That said, the variation in measurements of a given orthosis made with different subjects was minimized by subtracting subjects' intrinsic joint stiffness from the total stiffness to obtain the stiffness of each orthosis. Accordingly, the intraorthosis variability was relatively small, as indicated by the relatively small error bars in Figure 4.

How tight an orthosis is applied may potentially affect its stiffness. For our stiffness measurements to reflect typical orthosis usage, we instructed subjects to apply each orthosis themselves as if they would wear it for several hours. To validate this approach, we performed a small, informal prestudy in which we investigated whether the stiffness of a specific orthosis changed significantly with how tightly it was applied. First, we conducted a small survey in which we asked 10 nondisabled, college-aged subjects to apply one of the most common orthoses, orthosis 9 (Table $\mathbf{1}$ ), as if it would be worn for several hours. After subjects had applied the orthosis, we recorded the position of the orthosis straps, which directly affects orthosis tightness. We then measured the stiffness of the orthosis using the methods explained previously, with the straps in each of these 10 positions, and tested whether the variation in strap position affected the shape and magnitude of the resulting stiffness ellipse. The correlation between strap position and measured stiffness characteristics was found to be low ( $r^{2}$ values of 0.34 and 0.31 , respectively), indicating that the variation in orthosis tightness did not have a significant effect on orthosis stiffness - at least not within subjects' interpretation of applying it as if it would be worn for several hours.

\section{CONCLUSIONS}

Choosing an appropriate orthosis and improving the design and performance of orthoses requires that we understand how orthoses change joint stiffness. In this study, we developed a method to measure the stiffness of wrist orthoses and applied this method to four types of common wrist orthoses. This work provides previously unavailable information to distinguish between wrist orthoses on the basis of a (if not the) key property-stiffness. This information is valuable for health professionals prescribing wrist orthoses and for individuals self-prescribing wrist orthoses. It also lays the foundation for future research investigating the effects of orthosis stiffness on wrist rotation behavior and the future development of orthoses with stiffness properties designed to elicit the desired change in behavior specific to individual patients.

\section{ACKNOWLEDGMENTS}

\section{Author Contributions:}

Study concept and design: S. K. Charles, D. B. Seegmiller,

D. L. Eggett.

Acquisition of data: D. B. Seegmiller.

Analysis and interpretation of data: D. B. Seegmiller, D. L. Eggett. Drafting of manuscript: D. B. Seegmiller, S. K. Charles, D. L. Eggett. Statistical analysis: D. L. Eggett.

Study supervision: S. K. Charles.

Financial Disclosures: The authors have declared that no competing interests exist.

Funding/Support: This material was unfunded at the time of manuscript preparation.

Institutional Review: This study was approved by Brigham Young University's Institutional Review Board, and informed consent was obtained from all subjects.

Participant Follow-Up: The authors do intend to inform patients about the publication of this article.

\section{REFERENCES}

1. Coverdale JJ. An editorial note on nomenclature: Orthosis versus splint. J Hand Ther. 2012;25(1):3-4. http://dx.doi.org/10.1016/j.jht.2011.10.002

2. American Orthotic and Prosthetic Association. AOPA fact sheet [Internet]. Alexandria (VA): American Orthotic \& Prosthetic Association; 2015 [cited 2015 Oct 6]. Available from: http://www.aopanet.org/media/fact-sheet/

3. Deshaies LD. Upper extremity orthoses. In: Radomski MV, Latham CAT, editors. Occupational therapy for physical dysfunction. 6th ed. Baltimore (MD): Lippincott Williams \& Wilkins; 2008. p. 421-64.

4. Shu Y, Mirka GA. A laboratory study of the effects of wrist splint orthoses on forearm muscle activity and upper extremity posture. Hum Factors. 2006;48(3):499-510. [PMID:17063965] http://dx.doi.org/10.1518/001872006778606859

5. Bulthaup S, Cipriani DJ 3rd, Thomas JJ. An electromyography study of wrist extension orthoses and upper-extremity function. Am J Occup Ther. 1999;53(5):434-40. [PMID: 10500850] http://dx.doi.org/10.5014/ajot.53.5.434

6. Mell AG, Childress BL, Hughes RE. The effect of wearing a wrist splint on shoulder kinematics during object manipulation. Arch Phys Med Rehabil. 2005;86(8):1661-4. [PMID:16084823] http://dx.doi.org/10.1016/j.apmr.2005.02.008 
7. Yoo IG, Jung MY, Jeon HS, Lee J. Effects of wrist-extension orthosis on shoulder and scapular muscle activities during simulated assembly tasks. Ind Health. 2010; 48(1):108-14. [PMID:20160414]

http://dx.doi.org/10.2486/indhealth.48.108

8. Adams BD, Grosland NM, Murphy DM, McCullough M. Impact of impaired wrist motion on hand and upper-extremity performance. J Hand Surg Am. 2003;28(6):898-903.

[PMID:14642503] http://dx.doi.org/10.1016/S0363-5023(03)00424-6

9. King S, Thomas JJ, Rice MS. The immediate and shortterm effects of a wrist extension orthosis on upper-extremity kinematics and range of shoulder motion. Am J Occup Ther. 2003;57(5):517-24. [PMID:14527113] http://dx.doi.org/10.5014/ajot.57.5.517

10. Mell AG, Friedman MA, Hughes RE, Carpenter JE. Shoulder muscle activity increases with wrist splint use during a simulated upper-extremity work task. Am J Occup Ther. 2006;60(3):320-6. [PMID:16776399]

http://dx.doi.org/10.5014/ajot.60.3.320

11. Perez C, Buchholz B. A study of the use of a wrist splint to prevent WMSDs at a sprout grower. In: Proceedings of the Human Factors and Ergonomics Society Annual Meeting. Human Factors and Ergonomics Society 44th Annual Meeting; 2000 Jul 29-Aug 4; San Diego, CA. Santa Monica (CA): HFES; 2000. p. 225-228.

12. Bracoo. Neoprene wrist wrap [Internet]. Fremont (CA): Bracoo; 2016 [cited 2016 Dec 14]. Available from: http:// bracoo.com/product/breathable-neoprene-wrist-wrap/

13. Pando AL, Lee H, Drake WB, Hogan N, Charles SK. Position-dependent characterization of passive wrist stiffness. IEEE Trans Biomed Eng. 2014;61(8):2235-44. [PMID:24686225] http://dx.doi.org/10.1109/TBME.2014.2313532

14. Krebs HI, Volpe BT, Williams D, Celestino J, Charles, Lynch D, Hogan N. Robot-aided neurorehabilitation: A robot for wrist rehabilitation. IEEE Trans Neural Syst Rehabil Eng. 2007;15(3):327-35. [PMID:17894265] http://dx.doi.org/10.1109/TNSRE.2007.903899

15. An KN, Berger RA, Cooney WP, editors. Biomechanics of the wrist joint. New York (NY): Springer-Verlag; 1991.

16. Wu G, van der Helm FC, Veeger HE, Makhsous M, Van Roy P, Anglin C, Nagels J, Karduna AR, McQuade K, Wang X, Werner FW, Buchholz B; International Society of Biomechanics. ISB recommendation on definitions of joint coordinate systems of various joints for the reporting of human joint motion-Part II: Shoulder, elbow, wrist and hand. J Biomech. 2005;38(5):981-92. [PMID:15844264] http://dx.doi.org/10.1016/j.jbiomech.2004.05.042

17. Perreault EJ, Kirsch RF, Crago PE. Voluntary control of static endpoint stiffness during force regulation tasks. J Neurophysiol. 2002;87(6):2808-16. [PMID:12037183]
18. Drake WB, Charles SK. Passive stiffness of coupled wrist and forearm rotations. Ann Biomed Eng. 2014;42(9):1853-66. [PMID:24912766] http://dx.doi.org/10.1007/s10439-014-1054-0

19. Formica D, Charles SK, Zollo L, Guglielmelli E, Hogan N, Krebs HI. The passive stiffness of the wrist and forearm. J Neurophysiol. 2012;108(4):1158-66. [PMID:22649208] http://dx.doi.org/10.1152/jn.01014.2011

20. Axelson HW, Hagbarth KE. Human motor control consequences of thixotropic changes in muscular short-range stiffness. J Physiol. 2001;535(Pt 1):279-88.

[PMID:11507177] http://dx.doi.org/10.1111/j.1469-7793.2001.00279.x

21. de Leva P. Adjustments to Zatsiorsky-Seluyanov's segment inertia parameters. J Biomech. 1996;29(9):1223-30. [PMID:8872282] http://dx.doi.org/10.1016/0021-9290(95)00178-6

22. Dolan JM, Friedman MB, Nagurka ML. Dynamic and loaded impedance components in the maintenance of human arm posture. IEEE Trans Syst Man Cybern. 1993; 23(3):698-709. http://dx.doi.org/10.1109/21.256543

23. Mussa-Ivaldi FA, Hogan N, Bizzi E. Neural, mechanical, and geometric factors subserving arm posture in humans. J Neurosci. 1985;5(10):2732-43. [PMID:4045550]

24. Collier SE, Thomas JJ. Range of motion at the wrist: A comparison study of four wrist extension orthoses and the free hand. Am J Occup Ther. 2002;56(2):180-4.

[PMID:11905302]

http://dx.doi.org/10.5014/ajot.56.2.180

25. Carlson JD, Trombly CA. The effect of wrist immobilization on performance of the Jebsen Hand Function Test. Am J Occup Ther. 1983;37(3):167-75. [PMID:6846478] http://dx.doi.org/10.5014/ajot.37.3.167

26. Shih YC, Tsai BF. Splint effect on the range of wrist motion and typing performance. In: Dainoff M, editor. Lecture notes in computer science. Vol. 4566, Ergonomics and health aspects of work with computers. Berlin (Germany): Springer; 2007. p. 144-50.

27. Bland MD, Beebe JA, Hardwick DD, Lang CE. Restricted active range of motion at the elbow, forearm, wrist, or fingers decreases hand function. J Hand Ther. 2008;21(3): 268-74, quiz 275. [PMID:18652972] http://dx.doi.org/10.1197/j.jht.2008.01.003

28. Charles SK, Hogan N. Stiffness, not inertial coupling, determines path curvature of wrist motions. J Neurophysiol. 2012;107(4):1230-40. [PMID:22131378] http://dx.doi.org/10.1152/jn.00428.2011

29. Peaden AW, Charles SK. Dynamics of wrist and forearm rotations. J Biomech. 2014;47(11):2779-85. [PMID:24745814] http://dx.doi.org/10.1016/j.jbiomech.2014.01.053 
30. Charles SK, Hogan N. Dynamics of wrist rotations. J Biomech. 2011;44(4):614-21. [PMID:21130996] http://dx.doi.org/10.1016/j.jbiomech.2010.11.016

31. Palmer AK, Werner FW, Murphy D, Glisson R. Functional wrist motion: A biomechanical study. J Hand Surg Am. 1985;10(1):39-46. [PMID:3968403]

http://dx.doi.org/10.1016/S0363-5023(85)80246-X

Submitted for publication February 14, 2015. Accepted in revised form January 21, 2016.

This article and any supplementary material should be cited as follows:
Seegmiller DB, Eggett DL, Charles SK. The effect of common wrist orthoses on the stiffness of wrist rotations. J Rehabil Res Dev. 2016;53(6):1151-66.

http://dx.doi.org/10.1682/JRRD.2014.11.0274

ORCID: Dennis L. Eggett, PhD: 0000-0003-4109-4827;

Steven K. Charles, PhD: 0000-0003-4637-8482

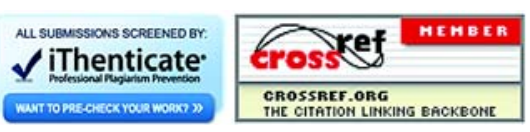


